\title{
Pharmaceutical policy reform in Canada: lessons from history
}

\author{
KATHERINE BOOTHE* \\ Associate Professor, Department of Political Science, McMaster University, Hamilton, ON, Canada
}

\begin{abstract}
Canada is the only country with a broad public health system that does not include universal, nationwide coverage for pharmaceuticals. This omission causes real hardship to those Canadians who are not well-served by the existing patchwork of limited provincial plans and private insurance. It also represents significant forgone benefits in terms of governments' ability to negotiate drug prices, make expensive new drugs available to patients on an equitable basis, and provide integrated health services regardless of therapy type or location. This paper examines Canada's historical failure to adopt universal pharmaceutical insurance on a national basis, with particular emphasis on the role of public and elite ideas about its supposed lack of affordability. This legacy provides novel lessons about the barriers to reform and potential methods for overcoming them. The paper argues that reform is most likely to be successful if it explicitly addresses entrenched ideas about pharmacare's affordability and its place in the health system. Reform is also more likely to achieve universal coverage if it is radical, addressing various components of an effective pharmaceutical program simultaneously. In this case, an incremental approach is likely to fail because it will not allow governments to contain costs and realize the social benefits that come along with a universal program, and because it means forgoing the current promising conditions for achieving real change.
\end{abstract}

Submitted 1 April 2017; revised 19 May 2017; accepted 1 July 2017; first published online 1 February 2018

\section{Introduction: why pharmacare?}

Canada is the only country with a broad public health system that does not include universal, nationwide coverage for pharmaceuticals. Although public pharmaceutical benefits vary internationally, in 2013 the only OECD countries with a smaller public proportion of pharmaceutical expenditures than Canada were the United States and Poland (OECD, 2015). This omission causes real hardship to those Canadians who are not well-served by the existing patchwork of limited provincial plans and private insurance. Surveys have found that one in 10 Canadians do not take their medicines as

*Correspondence to: Associate Professor Katherine Boothe, Department of Political Science, McMaster University, Hamilton, ON L8S 4L8, Canada. Email: boothek@mcmaster.ca 
prescribed because of cost (Law et al., 2012) and that even modest co-payments affect patients' ability or willingness to fill prescriptions (Morgan et al., 2015). Drug coverage varies significantly by province, both in terms of eligibility for provincial public insurance plans and the coverage offered by those plans (Grootendorst, 2002; Gagnon and Hebert, 2010; Pomey et al., 2010; Daw and Morgan, 2012). Canadians are accustomed to accessing hospital and medical services based on need, but access to pharmaceuticals is based on province of residence, age and often ability to pay. Canada's lack of universal pharmacare also represents significant forgone benefits in terms of governments' ability to negotiate drug prices, make expensive new drugs available to patients on an equitable basis, and provide integrated health services regardless of therapy type or location (Morgan and Willison, 2004). The lack of broad pharmaceutical insurance causes well-documented problems for Canadian citizens and Canadian health systems (Gagnon and Hebert, 2010; Morgan et al., 2015).

If the problems caused by the lack of broad pharmacare are well known, there is also growing consensus on the type of public program that could address these problems. In 2015, the Pharmaceutical Policy Research Collaboration (PPRC) at the University of British Columbia published Pharmacare 2020: The future of drug coverage in Canada which calls for universal, single-payer coverage of selected medicines at little or no direct cost to patients, with a publicly accountable management body that makes evidence-based decisions about coverage within a transparent budget (Morgan et al., 2015). At the time of writing, the Pharmacare 2020 recommendations have been endorsed by over 280 university-affiliated health professionals and researchers (see pharmacare2020.ca). In November 2016, PPRC researchers convened a Citizen's Reference Panel on Pharmacare, where a representative group of Canadians learned about pharmacare and deliberated on reform. The panel recommended a universal program covering a comprehensive, evidence-based list of drugs, and suggested a first step of immediate public coverage for a short list of basic, frequently prescribed drugs (Citizens Reference Panel on Pharmacare in Canada, 2016).

There are certainly competing recommendations. For example, the C.D. Howe Institute recently published a call for increased federal support for income-based plans in the provinces, and a focus on greater intergovernmental cooperation on drug price negotiation (Blomqvist and Busby, 2015). However, even these more limited recommendations acknowledge the current system is 'expensive and flawed' (Blomqvist and Busby, 2015: 12). The nature of the problem is well known, as are the key characteristics of a solution. Why, then, has there been so little progress on pharmaceutical policy reform?

\section{Is pharmacare 'unaffordable'?}

Pharmacare is often presented as a 'good policy idea' that is simply too expensive to implement. ${ }^{1}$ However, this paper argues that the idea of pharmacare's

1 See for example federal health minister Dr. Jane Philpot's comments to the CBC's Fifth Estate on 17 January 2017, available at http://www.cbc.ca/fifth/blog/full-interview-with-minister-of-health-jane-philpott 
unaffordability is a greater barrier to reform than the cost of a specific program at a given time. Comparative and historical research on the (non)development of pharmaceutical insurance in Canada, Australia and the United Kingdom suggests that Canada's lack of a broad nationwide pharmacare program can be attributed to its slow, incremental pace of health policy development, and the concomitant limited ideas that Canadian political elites have about health policy in general and pharmaceutical insurance in particular (Boothe, 2015). The cost of pharmaceutical insurance is certainly a barrier to reform, but it cannot explain why Canada initially rejected pharmaceutical insurance when other similar countries were adopting it, or why different proposals made in differing economic contexts over the years have failed.

Recent research into the cost of a universal pharmacare program suggests that the idea of pharmacare as fundamentally unaffordable is flawed. In an awardwinning article, Morgan et al. (2015) find that although universal, nationwide pharmaceutical insurance would cost governments about $\$ 3.4$ billion per year in additional spending, it would save the private sector about $\$ 8.2$ billion annually. The net savings to the total cost of pharmaceuticals in Canada would come from a reduction in the price of generic drugs, the price of branded drugs, and changes to product selection.

There are caveats to this analysis, of course. For example, since its publication, sales of sofosbuvir (brand name Solvadi) began in Canada. This is one of two new and expensive antiretroviral drugs to treat Hepatitis $\mathrm{C}$ that accounted for almost two-thirds of the 9\% increase in public drug spending between 2014 and 2015 (Canadian Institute for Health Information, 2016). Including it in the model would increase the projected cost to government. However, the model also understates potential savings to the health system by not accounting for better management of chronic diseases and a healthier population. Crucially, the study's authors argue that the reductions in the social cost of pharmaceuticals can only be achieved with the purchasing and negotiating power that comes with a universal public plan. It may be the case that there can be 'no pharmacare without cost control,' but unfortunately it is also the case that there can be only limited cost control without pharmacare.

Ultimately, whether $\$ 3.4$ billion or some other amount of additional public money is 'affordable' depends on which government pays and how the money is raised. But these issues tend not to be the focus of debate about pharmacare in Canada - instead discussions stall with the assumption that it is unaffordable. Understanding the history of these ideas and the way they interact with public expectations over time is key to understanding barriers to reform.

\section{Why does not Canada have pharmacare (yet)?}

Before turning to that history, it is necessary to discuss alternative explanations for Canada's failure to develop broad public pharmaceutical insurance. 
One possibility is that Canada does not have nationwide pharmaceutical insurance because health is a matter of provincial jurisdiction. Provinces are loath to give up control to the federal government, particularly in light of the federal government's tendency to withdraw financial support for shared cost programs over time. Additionally, or alternatively, Canada does not have universal pharmaceutical insurance because it was proposed 'too late': when the Royal Commission on Health Services recommended pharmaceutical insurance in 1964, the therapeutic revolution in pharmaceuticals was well underway and drug prices had begun their precipitous upward climb, making a broad public program unaffordable. Both factors present barriers to policy change. However, neither is ultimately a satisfactory answer for why five major national proposals for broad pharmaceutical insurance have failed, and focusing on these barriers alone risks missing important lessons from history about how to achieve pharmaceutical policy reform.

The 'too late/too expensive' explanation for Canada's lack of pharmacare is unsatisfactory in comparative perspective. Other countries considered and adopted broad pharmaceutical benefits during the immediate post-war period of welfare state development. For example, Australia and Britain share important similarities with Canada in terms of their political institutions and welfare state regimes, and although they developed their public health programs in very different ways, both had universal public drug benefits in place by the early 1950s. During this time, the Canadian federal government considered and rejected a proposal for broad public health insurance that would have included pharmaceuticals (Canada, 1945). Thus, a closer examination of the historical record in Canada changes the question from "why did Canada only consider pharmacare in 1964, when drugs were already prohibitively expensive?" to "why did Canada consider and reject pharmacare in the 1940s and 1950s, when other similar countries were adopting it?”

Using federalism as the primary explanation for Canada's lack of pharmacare is also unsatisfactory when examining the sequence and timing of reform proposals. Ascribing the failure of major proposals for nationwide pharmacare to federalprovincial disagreements alone ignores the fact that all these proposals were rejected at the federal level before they were an item of serious intergovernmental contention. The question of why nationwide pharmacare failed to gain a place on the federal government's agenda is therefore prior to the question of how proposals were blocked by federal institutions. Even if expectations about how these institutions would play out contributed to pharmacare's low place on the agenda, provincial opposition was not the only - or even the most frequently cited - reason for federal elites to oppose the development of pharmaceutical insurance.

This article argues that pharmacare is not fundamentally unaffordable, was not considered 'too late' in Canada, and is not made impossible by federal institutions. It acknowledges the barriers to reform posed by these factors, but contends that we can gain a more nuanced understanding of the barriers to change by studying 
the role of ideas and the pace of change in the failure of past proposals for nationwide pharmacare. The paper proceeds as follows. First, it outlines a theory of how an incremental pace of policy development interacts with elite ideas about a policy issue in a way that limits opportunities for reform. Here, 'elites' refers to elected policymakers. Bureaucrats are important sources of new ideas about policy and its goals, but politicians ultimately decide which items reach the government's action agenda and politicians are more likely to accept bureaucratic ideas if these ideas fit with their own existing beliefs about the policy (Jacobs, 2009; Carpenter, 2010: 258; Kingdon, 2003: 30-32). Policy ideas are expected to be most influential when they are shared (Denzau and North, 1994; Tuohy, 1999: 12). In a parliamentary system like Canada's, with power centralized in the executive, consensus on a policy idea among the Prime Minister and cabinet ministers is key, but I expect that the most persistent and influential policy ideas will be shared across party lines (Jacobs, 2009: 266).

Next, the article presents evidence regarding federal elites' early ideas about pharmaceutical insurance as unaffordable, and as an issue that was completely separate from the more publically salient issue of drug prices. The subsequent two sections review the failure of proposals for nationwide pharmacare in 1964, 1972, 1997 and 2002. They demonstrate that in each case federal institutions and financial considerations posed barriers to reform, but a prior and more influential set of barriers involved limited elite ideas and the corresponding limited electoral motivations for change. The final section asks what these lessons from history mean for policy change today.

\section{Adaptive expectations and pharmacare's low place on the agenda ${ }^{2}$}

When a country lacks centralized institutional authority, elite consensus on a 'big idea' about health policy or a public that is attentive to and supportive of the issue, as was the case in Canada during the 1940s and 1950s, it will tend to take a slower, incremental approach to policy development (Author, 2015). There may be discussion of a broad future goal, such as comprehensive public health services, but policy development is expected to proceed in stages, one program or component at a time. However, this initial choice of the pace of policy development places important constraints on opportunities for change over time. Later stages of an incremental process do not tend to proceed as natural or uncontested 'next steps.' Instead, they take on the characteristics of a radical change and require the same three conditions that were necessary to prompt a radical pace of change at an early critical moment. When these electoral, institutional and ideational conditions are met, radical change is possible, as was the case in Canada in the 1960s with the adoption of public, nationwide universal medical card insurance. Absent these conditions, limited policy ideas on the part of elites and limited public expectations tend to reinforce one another and block the adoption of additional services.

2 The following four sections rely heavily on Boothe (2015: Chs. 2 and 4). 
Ideas influence policy development as actors adapt their expectations regarding a policy area based on what has happened in the past, and these adaptive expectations influence their preferences and choices. Pierson (2000) has written about adaptive expectations in terms of political mobilization, pointing out that the self-fulfilling characteristics of expectations helps explain how people choose outlets for collective action. I focus on expectations about policy and extend these applications to include more explicitly the reciprocal causal relationship between elite ideas and public expectations. Early elite consensus on 'big' policy ideas (for example, that the government should provide free, universal coverage for most or all health services) influences public expectations for service by increasing awareness of the potential benefits, and this public awareness in turn promotes greater commitment from policymakers.

A slow pace of policy development has a significant impact on the development of public expectations for service. Incremental approaches to policy development are characterized by a lack of elite consensus on big policy ideas, and the public will not necessarily form independent expectations for a complex and multidimensional policy area. If the public is not prompted to expect additional services by politicians making policy promises, by high profile expert reports or recommendations, or by media coverage of such ideas (Noelle-Neumann, 1999: 68), there will be limited electoral motivations for expansion. Internal policy documents can provide evidence of plans for a broader program, but public discussion tends to be limited to the first priorities for service adoption - in Canada, hospital and medical insurance - and later, will focus on 'fixing what we have' rather than adding something new. Over time, both elites and the public maintain limited ideas about the range of relevant policy problems and solutions, the types of services they want or deserve, and the nature of additional services themselves, and this makes it difficult to expand the system.

If limited ideas are reinforced over time, it is important to try to understand their origins. This paper argues that two types of limited elite ideas were important in restricting opportunities for pharmacare in Canada: first, there was no early elite consensus on a 'big idea' about health policy that might have allowed for a radical pace of policy development, comparable to Britain's post-war consensus on the Beveridge report and the radical adoption of the National Health Service (Klein, 2010). Second, federal elites saw pharmaceuticals as unaffordable and unsuitable for government action from a very early period.

For the federal Liberal governments in the immediate post-war period, action on health was not an ideological imperative, but rather a political compromise based on electoral pressure from the Co-operative Commonwealth Federation, a social democratic party that was gaining power at both the provincial and federal level (Hacker, 1998: 97; Maioni, 1998: 74). The lack of consensus on health policy within the Liberal party is well documented in the memoirs of Paul Martin Sr., who was appointed Minister of National Health and Welfare in 1946 and became one of the few political champions of public health insurance within the 
federal government (Martin, 1985: 61). Martin struggled to get support from Prime Minister Mackenzie King, who was 'uneasy about the financial ramifications of health insurance' (Naylor, 1986: 131) and from King's successor, Louis St. Laurent. Beyond concerns about difficult federal-provincial negotiations or expense, it seems that St. Laurent simply did not perceive government health insurance to be a good policy idea. The Conservative premier of Ontario, Leslie Frost, pushed for hospital insurance's inclusion on the 1950 Federal-Provincial Conference agenda, and Martin reports that, "St. Laurent was taken aback. He did not believe in health insurance and was amazed that a Conservative premier would openly confess that he was for it" (Martin, 1985: 220). Instead, St. Laurent favored the expansion of voluntary insurance through existing private plans.

Elites' limited ideas about health policy helped block a radical pace of change, and their specific ideas about the potentially unaffordable nature of pharmaceuticals also meant this component had a low spot on the agenda. This was despite the fact that in the late 1940s and early 1950s, pharmaceuticals were clearly less expensive overall than hospital or medical care. Instead, it was policymakers' conclusions about the rate of cost increases that made a pharmaceutical program undesirable. Drugs were included as part of the 'later stages' of the first, failed 1945 proposals for federal-provincial cooperation on health services (Canada, 1945), but when the federal Department of Health and Welfare (DHW) reconsidered the order of priority for services in preparation for the 1950 FederalProvincial Conference, officials recommended leaving pharmaceuticals off the agenda entirely, because

...All the experience to date indicates that it is almost impossible to control the costs in such services, and, until something has been developed in this connection, we do not feel capable of making any suggestions at all as to cost (emphasis added) [Library and Archives Canada (LAC), 1949].

Why Canadian officials were more pessimistic about the possibility of controlling the costs of pharmaceutical benefits than other health services, or why they were more pessimistic than policymakers in other countries, is not clear. However, this reluctance to grapple with the financial implications of pharmaceuticals was persistent. In 1955, a meeting of federal and provincial deputy ministers of health concluded that pharmaceutical benefits were "not considered to be feasible at this stage...except for the necessary drugs which would be provided as part of the in-patient treatment services under a hospital care program" (LAC, 1955). In 1963, the federal Departmental Group to Study Health Insurance discussed pharmaceutical benefits in conjunction with the early work of the Royal Commission on Health Services. The minutes of the March 28 meeting note that while some members of the group wished to consider pharmaceutical benefits, others suggested "that in view of the difficulties inherent in the control of costs and in light of the availability of drugs provided in hospitals, that pharmaceutical benefits might be excluded from any Canadian medical care program” (LAC, 1963). 
The decision to place a low priority on pharmaceutical insurance is a result of the somewhat inexplicable way ideas about the costs of such services manifested themselves in the DHW in the late 1940s and 1950s. Canadian policymakers were making an explicit decision to take pharmaceuticals off the agenda, rather than simply arguing other services were comparatively more urgent. This decision had a long-term effect on politicians' ideas about the desirability and feasibility of a pharmaceutical program, and without elite discussion and prompting, pharmaceutical insurance also remained a low priority for voters, who instead focused on the more contentious and salient discussions of hospital and medical insurance.

\section{Drug prices vs drug insurance}

Although pharmaceutical insurance was little discussed in the early days of health policy development, pharmaceutical prices were becoming a greater public concern. In the late 1950s and early 1960s, public expectations and the electoral incentives they produced actually helped ensure the place of pharmaceutical price management on the federal government's agenda. Public complaints about drug prices were provided as the main rationale for the first federal investigation of drug prices, which began in 1958 with an internal report by the Director of Investigation and Research, Combines Investigation Act. The authors described their work as prompted by 'a large number of complaints that prices of drugs in Canada were exorbitant,' and 'informal complaints about the high cost of drugs' (Canada, Director of Investigations and Research, 1961). This occurred at the same time as a high profile investigation into monopolistic drug pricing by US Senator Estes Kefauver. ${ }^{3}$ It also coincided with increases in both the range of effective therapeutics and Canadians' out-of-pocket drug costs [Department of National Health and Welfare (Research and Statistics Division), 1964; Mann, 2004].

Between 1958 and 1969, drug prices were the subject of at least four more government inquiries, both internal and public. ${ }^{4}$ By 1965 , these various reports and investigations had produced a consensus that "Canadian drug prices [were] among the highest in the world," (LAC, 1965) and that drug manufacturers 'taking undue advantage of the tariff structure,' along with the current rules around drug patents, were to blame (Lang, 1974). The solution was a series of changes to patent law and drug tariffs, the centerpiece of which was a new allowance for compulsory licensing of imported pharmaceutical products. Compulsory licensing creates a legal requirement for a drug patent holder to let

3 Formal hearings before the Senate Anti-Trust and Monopoly Committee began in 1959, and resulted in the Kefauver-Harris Drug Control Act of 1962.

4 The studies were by the Restrictive Trade Practices Commission (Report Concerning the Manufacture, Distribution and Sale of Drugs, 1963), the Interdepartmental Committee on Drugs in 1964, the Royal Commission on Health Services (Hall Commission, 1964), and the Special Committee of the House of Commons on Drug Costs and Prices (Harley Commission 1966/1967). 
other firms produce its drug before the patent expires, in return for a specified level of royalties from the new generic product. ${ }^{5}$ This introduced competition between branded and generic medicines and had a significant impact on drug prices (Gorecki and Henderson, 1981: xii; Eden, 1989), but an unintended consequence was to further restrict elites' views of pharmaceutical policies in a way that made it very difficult for them to consider later proposals for pharmaceutical insurance. At this time, most public discourse did not link drug prices to universal drug insurance, even though a single purchaser of drugs would have an advantage in negotiating and perhaps regulating drug prices. It is unclear why this surprising disconnect occurred, but can be seen in the next two proposals for universal pharmacare in Canada: one included in the report of the Royal Commission on Health Services in 1964, and an internal proposal from the Department of National Health and Welfare that was considered by the federal Cabinet in 1972.

\section{4 and 1972: no pharmacare without cost control}

The report of the Royal Commission on Health Services was wide-ranging, recommending medical services, dental and optical services for certain populations, prescription drugs services, prosthetics and home care. It called for 'a comprehensive, universal Health Services Programme for the Canadian people,' although it acknowledged that each province might exercise 'the right to determine the order of priority of each service and the timing of its introduction' (Royal Commission on Health Services, 1964). The report was a key element in clarifying new health policy ideas at the federal level. It contributed to the exceptional circumstances that led to the adoption of nationwide universal medical coverage in Canada, almost a decade after the introduction of universal hospital coverage and despite the barriers posed by the expansion of both private and provincial systems for medical coverage (Author, 2015: 142-150). However, its recommendations for pharmaceutical coverage were not adopted or indeed seriously considered, and this can be explained by the entrenched ideas among federal elites that health policy development should proceed incrementally and that pharmaceutical insurance posed special challenges with regards to affordability.

The Royal Commission made two recommendations regarding pharmaceutical insurance. First, that the federal government make grants to the provinces 'for the purpose of introducing a Prescription Drug Benefit within the Health Services Programme,' and that these grants cover $50 \%$ of the cost of such a program. Second, that patients be required to make a 1 dollar 'contributory payment' for each prescription, although these might be waived for 'drugs required for longterm therapy' (Royal Commission on Health Services, 1964: 41).

These two recommendations were followed by an additional 23 numbered recommendations for controlling drug prices and costs. Despite the importance of

5 Compulsory licensing in Canada was abolished in 1993 (Douglas, 2008). 
pharmaceutical benefits to the overall goal of a comprehensive health service, the report devoted considerably more research and analysis to drug prices and patents. Interestingly, the discussions of drug prices and drug insurance were not connected in the report. The recommendation for a co-payment for pharmaceuticals and the focus on drug prices also served to set pharmaceuticals apart from medical coverage in terms of the type of policy problem they presented.

The DHW prepared draft comments in response to the Royal Commission's recommendations on pharmaceuticals, which noted that it would be possible to integrate 'prescription drug benefits with the Hospital Insurance and Diagnostic Services programme and a medical services insurance programme' as the report called for, and also that 'a more limited initial approach' to pharmaceuticals was possible, although the details of this approach were not included [LAC, n.d. (a)]. The department also provided a detailed response to the Commission's recommendations on drug prices. However, outside this one reference to the potential feasibility of including pharmaceuticals, which rested on the problematic assumption that the cost-sharing arrangements used for hospital coverage were still politically viable, there is no evidence that pharmaceuticals were part of the federal government's discussions or plans for health insurance at this time. In terms of political consideration, pharmaceutical benefits were completely overshadowed by the thorny problem of medical insurance, which became a major focus of federal-provincial negotiation over the next five years (Taylor, 1987; Bryden, 1997; Maioni, 1998). Although the Royal Commission's report is often considered the first major proposal for nationwide pharmacare in Canada, elites' limited ideas about the process of health policy development and the nature of pharmaceuticals as a policy problem meant it was not the subject of public discussion or intergovernmental negotiation.

The separation between pharmaceutical price management and pharmaceutical insurance, at least in the minds of political elites, is evident in the failure of a DHW proposal for a 'Drug Price Program' that would have linked the two issues. In 1971, the Minister of Health proposed a Drug Price Program that would include the extension of Medicare (as nationwide hospital and medical care coverage was known) to cover prescription drugs (LAC, 1971). The bureaucratic authors of the proposals clearly saw them as a principled policy choice that would not only reduce drug prices, which were an ongoing concerns despite the new patent laws (Lang, 1974: 248), but also fill a gap in the provision of health care and rationalize the use of existing public services. An unsigned draft memo from the DHW entitled 'Some Social Reasons for Pharmacare' argues that "society has come to think of health care as being part of a total system and as a result has recognized that an important segment of the health care system is not presently being covered by an insurance program," and furthermore, that "[i]t does not make much sense to pay a physician under Medicare to examine and prescribe for his patient if the patient is unable to benefit" because the prescription is unaffordable [LAC, n.d. (b)]. They recommended benefits be introduced on a universal basis, since the 
federal government would have the most bargaining power over prices as the single purchaser of drugs (LAC, 1972a).

These ideas about pharmaceutical insurance as a way to lower the combined public and private cost of pharmaceuticals contrast with the position of cabinet ministers. Consistent with their limited ideas concerning health and pharmaceutical policy, they did not consider the department's recommendation for a universal program, and seemed most concerned with containing the cost of pharmaceuticals to the federal government. In cabinet, the Prime Minister said, he did not wish to extend Medicare to outpatient drugs 'because of the considerable expenditures involved and the difficulty of getting the provinces to pay their share' (LAC, 1971). Ministers thought pharmaceutical coverage should be avoided because 'the government's first priority should be to restore public confidence in its economic policies' (LAC, $1972 \mathrm{~b}){ }^{6}$ and that 'pharmacare would be the beginning of a very expensive program which would undermine the confidence of the middle-income groups in the government's ability to control the budget' (LAC, 1972b).

Thus, DHW attempts to frame pharmaceutical insurance as a tool for price control failed, and this failure is a legacy of elites' ideas about the nature of both the drug price and drug insurance problems. The political elite had developed a consensus that patents caused high drug prices. This allowed for strong action in this policy area, but it also made it difficult for them to conceptualize the drug price issue in any other way. Despite the name of the proposal, in cabinet discussions of the Drug Price Program the issue of drug prices received few mentions. Cabinet ministers interpreted the proposals solely as a benefits program that had historically been dismissed for cost reasons. In the end, they decided pharmacare for seniors was only one of "various possible ways of providing further assistance to older people [that] should be considered in the more comprehensive financial content of the budget and deferred until such time as that could be done" (LAC, 1972b).

The limited discussion of drug insurance at the time of the Royal Commission report and the closed-door nature on the 1972 cabinet memo meant there were few opportunities for public expectations about pharmacare to develop, and this also served to keep pharmacare low on the policy agenda. A memo arguing for the Drug Price Program noted that federal departments "have received and continue to receive many letters from the public complaining about the high cost of prescription drugs and many requests that a drug insurance program similar to Medicare be made available" (LAC, 1972a). However, the same memo goes on to discuss strategies for implementing a program and says that since the federal government is not in a position to act unilaterally, it could "wait...for provincial and public pressures to build up," or actively encourage these pressures in hopes of igniting a desire for intergovernmental cooperation on the issue (LAC, 1972a). This suggests that proponents of pharmaceutical insurance recognized the

6 The recession of the mid-1970s had not yet hit and the economy was still reasonably strong at this point (Perry, 1989: 14-16). 
potential for public opinion to aid policy development, but that the necessary pressure did not yet exist.

Furthermore, most provinces did not begin to introduce targeted public drug benefits (for seniors and social assistance recipients) until the early 1970s, so Canadians' first experience with public coverage for drugs was both late and restricted to a relatively small portion of the population (Grootendorst, 2002). Private insurance was also limited: a 1964 study of prescription drugs in Canada reported that, "insurance against expenditures for prescribed drugs became available in Canada only recently, in a few prototype schemes" [Department of National Health and Welfare (Research and Statistics Division), 1964]. Certainly the campaign promises of political parties, and policy agendas of governments, never alluded to pharmaceutical insurance as anything other than a vaguely distant possibility. Although it is possible that the public was beginning to develop expectations about drug insurance based on a perceived 'gap' in the nowcomprehensive public hospital and medical insurance they enjoyed, there is little evidence for this kind of public pressure.

\section{7 and 2002: different plans, same ideas about pharmacare}

After the quiet failure of the 1972 Drug Price Program, pharmaceutical policy at the federal level continued on a track of managing prices and patents (Eastman, 1985; Douglas, 2008). The next federal attention to pharmaceutical coverage came in 1997, with the report of the National Forum on Health. The Forum was chaired by Prime Minister Jean Chrétien but drew its membership from nongovernmental policy experts, and was convened to fulfill a commitment in the 1993 Liberal 'Red Book' platform (Liberal Party of Canada, 1993: 78). Its final report, published in February 1997, made a bold recommendation for nationwide, public and universal pharmaceutical insurance: "Because pharmaceuticals are medically necessary and public financing is the only reasonable way to promote universal access and to control costs, we believe Canada should take the necessary steps to include drugs as part of its publicly funded health care system" (National Forum on Health, Canada, 1997).

Pharmacare was endorsed in the June 1997 Liberal platform 'as a long-term national objective,' (Liberal Party of Canada, 1997) and mentioned as an area of focus in the Health Transition Fund announced in the November 1997 Speech from the Throne (Canada, Governor General, 1997). However, these promising beginnings did not result in significant policy development. According to Marie Fortier, Executive Director for the Secretariat of the Forum and former Associate Deputy Minister of Health, "after the Forum, the whole idea of national pharmacare sort of fell down...in a black hole." ${ }^{7}$ When pharmaceuticals next

7 Marie Fortier, interview, Ottawa, 15 October 2008. The following sections draw on 11 interviews conducted by the author with individuals with expertise in federal health and pharmaceutical policy. Interviewees are cited by name or by their chosen designation. 
appeared on the federal government's public agenda in 2000, the focus had returned to pharmaceutical management policies (Canada, 2000).

When explaining the failure of the National Forum proposals, commentators often describe them as mistimed: they came when the country was still recovering from a severe recession, and after four years of deep cuts to federal health transfers to the provinces (Treff and Perry, 1997, 1998). Provincial governments were angered by the federal changes to health transfers and only beginning to recover themselves, and were in no mood to negotiate what they called 'boutique programs,' according to Paul Genest, a former advisor to two federal health ministers. ${ }^{8}$ These immediate circumstances clearly had a role in the failure of the National Forum plan, but I argue elites' limited policy ideas and correspondingly limited public expectations were crucial barriers. These ideas regarding pharmaceuticals and the scope of the health system, which developed in the 1940s and 1950s and blocked policy expansion in 1964 and 1972, were also evident in this later policy episode, preventing the extraordinary ideational and electoral circumstances that might have overcome immediate institutional and fiscal hurdles.

The incrementalist focus on 'fixing what we have' vs 'adding something new' was shared by elites at both the federal and provincial levels. Marie Fortier suggests when the National Forum reported, it was "too early in the post-deficit years to think about something big like [pharmacare], also some of the cuts were still hurting...There was a lot of anger [in the provinces] about the...reductions overall in transfers." 9 The Honorable Roy Romanow, who was premier of Saskatchewan when the National Forum report was published, confirmed this sense of provincial attitudes. He recalls that most premiers at the time were "more preoccupied with the withdrawal of federal funding to the overall healthcare system in the 1990s... than it was about specific programs." ${ }^{10}$ Genest did not think the provinces took the National Forum's pharmacare proposals seriously enough, but also admitted that "when they're having trouble affording bread and butter and we're saying, let's work on cheese, you can appreciate their point of view." 11 A sense of crisis about the sustainability of existing services precluded the possibility of drawing positive lessons that might apply to pharmaceuticals. In 2008, Abby Hoffman, assistant deputy minister in Health Canada in charge of pharmaceutical management policies, summed up the lack of serious attention to pharmaceutical insurance by federal governments: "I think, reflecting back on the last fifteen years, I don't see any government actually seriously saying, the next building block in the evolution of Canadian medicare is a comprehensive, universal pharmacare regime...nobody has gone down that road." ${ }^{2}$

8 Paul Genest, interview, Ottawa, 24 October 2008.

9 Fortier, interview.

10 The Honorable Roy Romanow, interview, Saskatoon, 31 October 2008.

11 Genest, interview.

12 Abby Hoffman, interview, Ottawa, 16 October 2008. 
This limited idea of what the health system should do posed an important barrier to reform, but so did a limited idea of pharmaceutical insurance itself. A policy advisor remembers that during the deficit period, "The fear of opening the floodgates to something hugely expensive and uncontrollable [like pharmacare], which you could never take away from anybody, was there for everybody."13 Similarly, Hoffman said that after the National Forum, "there wasn't real political appetite to really carry these ideas forward...even if there was some sort of publicly and privately funded universal program, the costs were just regarded as so daunting." She went on: "Even if...a universal system would provide more access and be less burdensome on the economy than this fragmented mess that we have today, this is a great example of a terrific academic idea...that is impossible to sell, and it will continue to be impossible to sell as long as costs...go up at the rate they are going up." 14

As in previous periods, the absence of strong political backing for an expert proposal on pharmaceutical insurance contributed to limited public salience, which in turn reinforced elites' limited ideas about the feasibility and desirability of a nationwide pharmaceutical program. There are few direct measures of public awareness of or support for broad public pharmaceutical insurance at this time. However, the relevant polls do suggest that public attention to health issues was firmly focused on the problems of existing services (Environics Canada, 1997-1 and 1997-2), while elites tended to focus on existing services and the growing role of private drug insurance for some Canadians in dampening the salience of pharmacare.

Elites consistently and without prompting cited the prevalence of private, employer-sponsored drug insurance for the middle class, and the high levels of concern about the problems of the existing system of medical and hospital insurance, such as wait times and overcrowded hospital emergency rooms, as reasons that the public did not pay attention to proposals for universal pharmaceutical insurance. Hoffman offered that while there are significant numbers of Canadians without sufficient drug coverage, 'it is not something that affects a large number of Canadians all the time.' She noted that Canadians are concerned about wait times and doctor shortages, but drugs have not captured the public imagination. ${ }^{15}$

Jane Coutts, a former health reporter for the Globe and Mail newspaper who covered the National Forum on Health, suggested that Canadians did not focus on pharmaceutical coverage because they were (and largely still are) insulated by private, employer-sponsored drug plans or public plans for seniors in most provinces, but wait times for hospital and medical services were much more visible. However, she also cited the legacy of limited expectations about pharmaceutical coverage, saying, “They [Canadians] don't expect it. They expect fast care...but

13 Policy advisor, interview, Toronto, 23 October 2008.

14 Hoffman, interview.

15 Hoffman, interview. 
[pharmacare] has never been part of medicare, and never seems as urgent.”16 Another political advisor commented on the media attention directed towards overcrowded emergency rooms in the late 1990s, saying "it was on the news every night...it was like a national disaster," and this greatly increased the pressure to boost transfers to provinces for primary care. He contrasted this issue with pharmacare, which he said, "probably wouldn't come up as a top-of-mind issue," for voters. ${ }^{17}$

These assessments are borne out in public opinion polls in 1997 and 1998. Beyond concern with problems in existing health services, there was a high level of concern with economic problems. Voters were concerned about health care and supportive of increased health spending when questioned about it directly, but their response regarding the most important problem facing Canadians was unemployment and the economy. At the beginning of 1997 these were the most frequent responses at $43.6 \%$ and $11.7 \%$, respectively, while 'other health/medical' was the most important problem for only $4.4 \%$ of respondents (Environics Canada, 1997-1).

A poll at the end of the year asked voters about their knowledge of the Speech from the Throne, where the government set out their agenda for the coming parliamentary session. This provided an unusual opportunity to observe voters' knowledge of pharmacare promises, since they were mentioned in the Throne Speech (Canada, Governor General, 1997). However, only $21.5 \%$ of respondents were 'somewhat familiar' or 'very familiar' with the speech, and only $1.7 \%$ of these reported that mention of a drug plan had attracted their attention, compared with $8.6 \%$ who noticed the promise of a balanced budget, and $5.4 \%$ who noticed a promise to restore funding for health care (meaning hospital and medical services) (Environics Canada, 1997-2). The implications of these results are that the limited elite discussion of pharmacare had not drawn public attention away from the higher-profile issues of general reinvestment in health services - 'fixing what we have' - and therefore the public did not provide any clear electoral motivations for politicians to act on pharmacare.

This relationship between limited elite ideas and limited public expectations is also evident in the reports of the Commission on the Future of Health Care in Canada (the Romanow Report) and the Report of the Standing Senate Committee Social Affairs, Science \& Technology (the Kirby Report). Both Romanow and Kirby reported in 2002, and federal and provincial governments responded to their recommendations in two Health Accords, or intergovernmental agreements for health policy development, in 2003 and 2004.

The pharmacare proposals in both reports respond to some of the major concerns with earlier options by outlining a more limited goal of 'catastrophic drug coverage,' where citizens would be protected against drug expenses exceeding a

16 Jane Coutts, interview, Ottawa, 15 October 2008.

17 Political advisor, interview, Ottawa, 21 October 2008. 
certain portion of their incomes. The reports also came during relatively good economic times, when the federal government presented its fifth consecutive balanced budget and debt-reduction targets continued to be met (Treff and Perry, 2002, 2003). Despite these differences in the details of the plan and the economic circumstances, however, the calls for nationwide catastrophic drug coverage failed for the same reasons the calls for first-dollar coverage did in earlier periods. First, because of restricted policy ideas on the part of elites that told them fixing existing services was more important than expanding services, that pharmaceutical coverage of any type was not analogous to existing services, and that initiating this type of benefit would result in an expensive program with no potential for cost control. Second, because of public expectations that mirrored and reinforced those ideas.

The reports' authors tend to cite situational factors in explaining why their recommendations were not adopted on a national level. Senator Wilbert Keon, a member of the Senate Standing Committee, argued that Kirby's catastrophic drug coverage proposals failed because of the lack of an individual or group at the provincial or federal level to handle the issue, although he also noted criticism of the proposal as potentially extremely expensive. ${ }^{18}$ Roy Romanow was generally positive about what the commission achieved but noted that, 'the report fell into the Martin-Chrétien battle,' when leadership of the governing federal Liberal party was in question, and this hampered adoption of its recommendations. ${ }^{19}$

However, the response of federal policy advisors and observers reflects the influence of longstanding policy ideas about pharmaceuticals and the scope of the health system as well. Interviewees emphasized the degree to which pharmaceutical coverage competed with other reform priorities (a focus on 'fixing what we have') as well as the barriers posed by cost, the desirability of focusing on management as a more feasible policy option, and also jurisdictional issues.

A senior federal official involved in planning the 2003 and 2004 First Ministers' Meetings sums up these barriers, saying 'caution was the order of the advice.' $\mathrm{He}$ said the 2003 Health Reform Fund was 'a classic example' of the problem of multiple priorities: "We have a number of priorities overall. Getting deeply into this one [pharmacare] could be very expensive and could detract from our focus on those other areas." He went on to say pharmaceutical insurance was less attractive than other issues because 'analytically and in policy terms, it was extremely complex... and it is costly.' Finally, there was the jurisdictional issue, "did the federal government want to get involved...in actually administering a program. ${ }^{20}$ Fortier indicates that in 2004, questions of pharmaceutical insurance and management were separate and management was emphasized because 'everyone deliberately wanted to make progress on pharmaceuticals without

18 Senator Wilbert Keon, interview, by phone, 6 November 2008.

19 Romanow, interview.

20 Senior federal official, interview, Ottawa, 16 October 2008. 
having to open the insurance can of worms.' According to her, pharmacare 'is kind of a non-story, really, because with pharmaceuticals, at least the insurance side of it, has just been dismissed time and time again. ${ }^{21}$

Assessing public expectations for expanded public drug insurance after the Romanow and Kirby reports is problematic, because there is a lack of publically available polling data on how aware voters were of the reports, and the recommendations of which they were most aware. Certainly pharmaceutical insurance was a low priority for Canadians prior to the reports' release. Mendelsohn (2002) reports on a qualitative research project around this time that asked Canadians to rank their goals for health system reform and found that 'adequate numbers of nurses, doctors and specialists across the country' was the top priority, while pharmacare was the lowest - a finding he notes was repeated in 'a large survey conducted around the same time' (Mendelsohn, 2002: 15).

The release of the Romanow and Kirby reports generated slightly more media coverage of pharmaceutical insurance than the National Forum on Health in terms of the number of substantive newspaper articles (Daw et al., 2013: figure 2). However, neither report received extensive coverage, and while a nationwide, universal pharmacare program was one of three major recommendations by the National Forum (along with home care and improved health information systems), the smaller-scale proposals for catastrophic drug coverage were one of 23 recommendations from the Kirby Report, and 47 recommendations from Romanow. In the absence of clear evidence that catastrophic drug coverage stood out in the public's mind and the fact that it was one part of a comprehensive set of recommendations for reform, it is possible that it was even less publically salient than the National Forum's earlier pharmacare proposal.

Looking back on this time, my interviewees were in consensus about the lack of public salience of expanded public drug insurance. This is significant because even if a variety of advisors all made the same mistake about public opinion, their assessments were being passed on to politicians. Their assessment of low public salience in 2002 was similar to 1997 and was based on two factors: the public was more concerned about fixing or funding existing services (for example, dealing with wait times for hospital and medical services), and the idea that a combination of private and targeted provincial insurance programs served most people fairly well.

Keon explains the Senate committee's decision to focus on catastrophic drug coverage, saying that although the patchwork of provincial plans was complex, the coverage it provided was generally acceptable: "the one outstanding issue... was individuals who were subjected to catastrophic costs." 22 Owen Adams, the assistant secretary general in charge of policy analysis for the Canadian Medical Association, argued that in terms of public attention, pharmacare "is losing in the

21 Fortier, interview.

22 Keon, interview. 
competition... and governments know this. Expanding medicare doesn't roll... because most Canadians have some kind of [pharmaceutical] coverage." 23

Two Liberal policy advisors offered more direct insights into the government's priorities for health reform in the early 2000s. Fortier noted that although pharmacare was mentioned in 2003 and 2004 Health Accords, Prime Minister Martin and his team chose to focus on wait times, and put a lot of money into it, because "they were looking for something that affected people and that people understood. Wait times were a big top-of-mind issue at the time." ${ }^{24}$ Genest echoed this view, saying that on 2004 Accord,

I think they went for popular pieces: wait times was way up on the radar screen of what the public wanted; pharma policy was merely good and sound policy but so many people had private insurance...The Martin government was very much a poll-driven government, and because it wasn't way up there in the polls, they decided to put their eggs in the wait times basket. ${ }^{25}$

Steven Lewis, a policy advisor and researcher who was a member of the National Forum and also involved in the Romanow Commission, reiterated that pharmacare stays off the agenda because the middle class has private insurance and most provinces provide coverage for seniors. As he eloquently put it, "I think the public's expectations have been stripped in this area. They have bought the argument that it's not affordable, even though they are paying for it in the end." 26

\section{Conclusion: what does this mean for reform?}

This paper began by arguing that Canadians know what to do about pharmacare the harms caused by a lack of broad public pharmaceutical coverage are well understood, and there is a reasonable degree of expert consensus on the type of program could mitigate these harms and realize important benefits in terms of lower drug prices and costs, more equitable access to necessary therapies, and better health outcomes for Canadians. The difficulty is in knowing how to do it, and the history of pharmacare proposals in Canada provides two main lessons in this regard.

The first lesson is that to achieve changes to Canada's limited and fragmented pharmacare programs, reformers must address ideational and electoral barriers to change, as well as (and perhaps before) institutional barriers. Over time, the idea that pharmacare is prohibitively expensive and subject to uncontrollable costs has become an article of faith with elites, an idea that is not supported by evidence. Many similar countries provide universal public coverage of pharmaceuticals and are better at controlling costs than Canadian drug plans are currently, and when it comes to combined public and private spending on pharmaceuticals, Canada pays

23 Owen Adams, interview, Ottawa, 21 October 2008.

24 Fortier, interview.

25 Genest, interview.

26 Steven Lewis, interview, Saskatoon, 31 October 2008. 
more per capita than almost all OECD countries apart from the United States (Canadian Institute for Health Information, 2016). Furthermore, new research on projected costs of universal pharmacare in Canada suggests that they could be both predictable and relatively modest, especially in comparison to the potential savings to the private sector (Morgan et al., 2015). Experts have a role in communicating this type of evidence to political elites and to the public in a way that is clear, accurate and accessible.

Communicating new ideas about pharmacare to the public is essential, because one way to generate the political will for change among elites is to demonstrate a public appetite for it. An Angus Reid poll in 2015 questioned Canadians about their support for pharmacare, and found that $85 \%$ of respondents agreed or strongly agreed with the statement: 'It only makes sense that medicine should be part of medicare' (Angus Reid Institute, 2015). When asked about the level of priority they placed on improving prescription drug access and affordability, $81 \%$ of respondents classified access and affordability of drugs as a 'high' or 'very high' priority (Angus Reid Institute, 2015). However, the report goes on to note that 'separate line of questioning found 60 per cent agreement with the statement: "There are lots of other higher priority issues facing the health care system right now",' and 40\% of respondents believe that Canada 'simply can't afford universal drug coverage' (Angus Reid Institute, 2015). This suggests that although Canadians are broadly supportive of pharmacare, concerns about its affordability and its level of priority relative to other health reforms are still influential. This has implications for the types of messaging that may be effective in mobilizing public expectations for reform, particularly since increases in pharmaceutical costs to government are predicted to be more than offset by private savings.

We have an example of the power of elite consensus on a cohesive 'big idea' about health policy reform coupled with high levels of public salience in the adoption of universal public medical coverage in Canada. After the introduction of nationwide public hospital coverage in 1957, federal policymakers expected that medical coverage would be the uncontroversial next step. However, it turned out to be a significant political struggle in the face of increasing reluctance from the provinces and medical associations, and outright opposition from the operators of commercial and physician-sponsored medical insurance. Nationwide medical coverage in Canada was possible in the mid-1960s because the public was in favor of it, and was paying close attention to the issue; the usual barriers to nationwide policy posed by federalism were temporarily lowered by the federal government's willingness to compromise with the provinces on program design and make a real financial contribution; and crucially, there was new leadership and new policy ideas at the federal level - in other words, political will. In the mid1960s, the conditions for change with regards to medical insurance were favorable, but some of the most important conditions - elite ideas and the degree of public attention to the policy - can be reshaped by motivated reformers.

The second lesson is that the pace of change matters. The incremental approach to early Canadian health policy development was perhaps inevitable given the 
institutional, ideational and electoral conditions that prevailed in the late 1940s and early 1950s. However, understanding the barriers to later policy development posed by an incremental process should make us wary of proposals to expand pharmaceutical coverage incrementally. Even if there appears to be agreement on 'someday' goals for pharmacare (but especially if these goals are contested), Canadian experience suggests that proceeding one step at a time makes it less likely that universal pharmacare will be achieved.

The risks of incrementalism can be seen in the provincial adoption of catastrophic pharmaceutical insurance. Although the Romanow Commission's recommendation for catastrophic coverage was not adopted on a nationwide basis, over the past 15 years this type of high deductible insurance has been implemented to varying degrees in most Canadian provinces. The Romanow Commission thought that catastrophic insurance would act as a stepping-stone to a later universal program, while providing relief to Canadians who were burdened by very high drug costs. However, catastrophic insurance tends not to provide momentum for reform because it requires a financial commitment but does not provide governments with efficiencies and benefits of a universal program, such as the bargaining power vis-à-vis drug manufacturers that would result from having a single or coordinated purchaser of pharmaceuticals. It fails to meet the criteria of equity and accessibility, since it results in individuals assuming high out-of-pocket costs for drugs - what amounts to a tax on the sick - and even modest patient charges reduce the likelihood that the most vulnerable members of our society will fill necessary prescriptions (Morgan et al., 2013). Mr. Romanow himself has acknowledged that the catastrophic approach has not achieved the benefits that were hoped for, and has joined researchers in calling for a universal, single-payer program (Romanow and Marchildon, 2015).

The history of health reform in Canada, and particularly the history of pharmacare proposals in Canada, suggests that successful reform must account for ideational barriers that say pharmacare is fundamentally unaffordable, and that it is somehow a separate and less important issue than 'fixing' existing health services. This means the continuation of clear and persistent communication efforts focused on the public and private costs of universal pharmacare, as well as the financial and human costs of forgoing broad drug coverage. It means drawing explicit links between pharmaceutical services and other aspects of the health system, and to the ways a well-designed pharmacare program can improve what Canadians tend to think of as 'core' health services. History also suggests that starting with only one component of a planned universal program is risky, as incremental processes, in this domain at least, are more likely to stall than to follow a natural progression of expansionary development.

These lessons for reformers come with an important caveat: changing ideas is slow and difficult work, and elite consensus on these ideas is likely required across federal and at least some provincial governments. Recently, there has been some increase in federal and provincial attention to pharmaceutical insurance. The House of Commons Standing Committee on Health is completing an in-depth on national 
pharmacare (Standing Committee on Health, 2017). The province of Ontario made headlines in May 2017 with its announcement of universal coverage of prescription drugs for Ontarians under the age of 25, regardless of income (Ontario, Office of the Premier, 2017). However, entrenched ideas about pharmacare's unaffordability persist. In January 2017, Canada's federal minister of health, Dr. Jane Philpot, spoke the CBC's Fifth Estate and emphasized her commitment to improving Canadians' access to necessary medicines, but also contented that it would be 'irresponsible' to develop a broad system of pharmaceutical insurance or benefits given the high prices of drugs in Canada (The Fifth Estate, 2017). It remains to be seen whether the lessons of history regarding pharmacare result in policy reform.

\section{Acknowledgments}

I thank Greg Marchildon, Colleen Flood, and the participants in the Associated Medical Services' 80th Anniversary Symposium for their guidance and suggestions. I also thank the journal's anonymous reviewers for helpful comments on the article. This research was supported by a fellowship from the Social Science and Humanities Research Council of Canada. The article is based on material from Katherine Boothe, Ideas and the Pace of Change: National Pharmaceutical Insurance in Canada, Australia, and the United Kingdom (c) University of Toronto Press 2015. Used with permission of the publisher.

\section{References}

Angus Reid Institute (2015), Prescription Drug Access and Affordability an Issue for Nearly a Quarter of All Canadian Households, Ottawa: Angus Reid Institute.

Blomqvist, A. and C. Busby (2015), Feasible Pharmacare in the Federation, Ottawa: C.D. Howe Institute.

Boothe, K. (2015), Ideas and the Pace of Change: National Pharmaceutical Insurance in Canada, Australia, and the United Kingdom, Toronto: University of Toronto Press.

Bryden, P. (1997), Planners and Politicians: Liberal Politics and Social Policy, 1957-1968, Montreal, Kingston: McGill Queens University Press.

Canada (1945), Dominion-Provincial Conference on Reconstruction: Plenary Conference Discussions, Ottawa: King's Printer.

Canada (2000), 'First Ministers' Meeting Communique on Health', Canadian Intergovernmental Conference Secretariat, Ottawa.

Canada, Director of Investigations and Research (1961), 'Material Collected for Submission to the Restrictive Trade Practices Commission in the Course of an Inquiry Under Section 42 of the Combines Investigation Act, Relating to the Manufacture, Distribution and Sale of Drugs', Department of Justice, Ottawa, Appendix Q to RTPC Report.

Canada, Governor General (1997), 'Speech from the Throne - 36th Parliament', Privy Council Office, Ottawa, 12 July.

Canadian Institute for Health Information (2016), Prescribed Drug Spending in Canada, 2016, Ottawa: Canadian Institute for Health Information.

Carpenter, D. P. (2010), Reputation and Power, Princeton, NJ: Princeton University Press. 
Citizens Reference Panel on Pharmacare in Canada (2016), Necessary Medicines: Recommendations of the Citizens' Reference Panel on Pharmacare in Canada, Vancouver: Citizens Reference Panel on Pharmacare in Canada.

Daw, J. R. and S. G. Morgan (2012), 'Stitching the gaps in the Canadian public drug coverage patchwork? A review of provincial pharmacare policy changes from 2000 to 2010', Health Policy, 104(1): 19-26.

Daw, J. R., S. G. Morgan, P. A. Thomson and M. R. Law (2013), 'Here today, gone tomorrow: The issue attention cycle and national print media coverage of prescription drug financing in Canada', Health Policy, 110(1): 67-75.

Denzau, A. T. and D. C. North (1994), 'Shared Mental Models: Ideologies and Institutions', Kyklos, 47(1): 3-31.

Department of National Health and Welfare (Research and Statistics Division) (1964), Provision, Distribution and Cost of Drugs in Canada, Ottawa: Queen's Printer.

Douglas, K. (2008), Patent Protection for Pharmaceutical Products in Canada-Chronology of Significant Events, Ottawa: Parliamentary Research and Information Service.

Eastman, H. (1985), Report of the Commission of Inquiry on the Pharmaceutical Industry, Ottawa: Supply and Services Canada.

Eden, L. (1989), 'Compulsory Licensing and Canadian Pharmaceutical Policy', in A. M. Rugman (ed.), International Business in Canada: Strategies for Management, Scarborough, ON: Prentice Hall, 245-267.

Environics Focus Canada Polls (1997-1 and 1997-2), 'Canadian Opinion Research Archives', queensu.ca/cora [1 September 2009].

The Fifth Estate (2017), Full Interview with Minister of Health Jane Philpott, Ottawa: Canadian Broadcasting Corporation. http://www.cbc.ca/fifth/blog/full-interview-withminister-of-health-jane-philpott.

Gagnon, M.-A. and G. Hebert (2010), The Economic Case for Universal Pharmacare, Ottawa: Canadian Centre for Policy Alternatives.

Gorecki, P. K. and I. Henderson (1981), 'Compulsory patent liscensing of drugs in Canada: a comment on the debate', Canadian Public Policy, 7(4): 559-568.

Grootendorst, P. (2002), 'Beneficiary cost sharing under Canadian provincial prescription drug benefit programs: history and assessment', The Canadian Journal of Clinical Pharmacology, 9(2): 79-99.

Hacker, J. S. (1998), 'The historical logic of national health insurance', Studies in American Political Development, 12: 57-130.

Jacobs, A. M. (2009), 'How do ideas matter?: Mental models and attention in German pension politics', Comparative Political Studies, 42(2): 252-279.

Kingdon, J. W. (2003), Agendas, Alternatives and Public Policies, New York: Longman.

Klein, R. (2010), The New Politics of the NHS: From Creation to Reinvention, New York: Longman.

Lang, R. W. (1974), The Politics of Drugs: A Comparative Pressure-group Study of the Canadian Pharmaceutical Manufacturers Association and the Association of the British Pharmaceutical Industry, 1930-1970, Farnborough, Hants and Lexington, MA: Saxon House and Lexington Books.

Law, M. R., L. Cheng, I. Dhalla, D. Heard and S. G. Morgan (2012), 'The effect of cost on adherence to prescription medications in Canada', Canadian Medical Association Journal, 184(3): 297-302.

Liberal Party of Canada (1993), Creating Opportunity: The Liberal Plan for Canada (Red Book), Ottawa: Liberal Party of Canada. 
Liberal Party of Canada (1997), Securing Our Future Together: Preparing Canada for the 21st Century, Ottawa: Liberal Party of Canada.

Library and Archives Canada (n.d.(a)), 'Draft Comments on Hall Commission, Prescription Drug Services - Benefits (circa 1966)', RG 29, Vol 1129 File 504-4-15 pt 2, Department of Health Fonds.

Library and Archives Canada (n.d.(b)), “DRAFT - Some Social Reasons for Pharmacare” and “Arguments for Pharmacare” (circa 1972)', RG 29 Vol 1572 File 1016-1-2, Department of Health Fonds.

Library and Archives Canada (1949), 'Health Insurance brief', RG 29 Vol 1061 File 500-3-4 pt.1, 7 December, Department of Health Fonds.

Library and Archives Canada (1955), 'Draft Report to the Chairman of the Preparatory Committee for the Federal-Provincial conference 1955 on a Personal Health Care Program', RG 29 Vol 1132 File 504-5-6 pt.1, Department of Health Fonds.

Library and Archives Canada (1963), 'Meeting of the Departmental Group to Study Health Insurance', RG 29 Vol 1129 File 504-4-15 pt 1, 27 March, Department of Health Fonds.

Library and Archives Canada (1965), 'Possible action on drug prices', RG 33-78 Vol 51, R. B. Bryce to Health Minister Judy LaMarsh, 16 March 1965, Royal Commission on Health Services in Canada Fonds.

Library and Archives Canada (1971), 'The Drug Price Program', Memo, RG2 Vol 6381 Series A-5-a, 23 September, Privy Council Office Fonds.

Library and Archives Canada (1972a), Memorandum to Cabinet, "Measures to lower the unit cost of prescription drugs including a drug benefit program [Pharmacare-handwritten]", RG2 Vol 6397 File 120-72, 2 and 8 February, Privy Council Office Fonds.

Library and Archives Canada (1972b), 'Memorandum to Cabinet: "Measures to lower the unit price of drugs including a drug benefit program”, RG2 Series A-5-a 23 March, 30 March, Privy Council Office Fonds.

Maioni, A. (1998), Parting at the Crossroads, Princeton, NJ: Princeton University Press.

Mann, J. (2004), Life Saving Drugs: The Elusive Magic Bullet, Cambridge: Royal Society of Chemists.

Martin, P. (1985), A Very Public Life Volume 2 Toronto: Deneau.

Mendelsohn, M. (2002), Canadians' Thought on Their Health Care System, Ottawa: Commission on the Future of Health Care in Canada. queensu.ca [20 July 2015].

Morgan, S. G. and D. Willison (2004), 'Post-Romanow pharmacare: last-dollar first... firstdollar lost?', Healthcare Papers, 4(3): 10-20.

Morgan, S. G., J. R. Daw and M. R. Law (2013), Rethinking Pharmacare in Canada, Toronto: C.D. Howe Institute.

Morgan, S. G., M. Law, J. R. Daw, L. Abraham and D. Martin (2015), 'Estimated cost of universal public coverage of prescription drugs in Canada', Canadian Medical Association Journal, 187(7): 491-497.

Morgan, S. G., D. Martin, M.-A. Gagnon, B. Mintzes, J. R. Daw and J. Lexchin (2015), Pharmacare 2020: The Future of Drug Coverage in Canada, Vancouver: The Pharmaceutical Policy Research Collaboration, University of British Columbia. pharmacare2020.ca [3 February 2017].

National Forum on Health, Canada (1997), Canada Health Action: The Final Report of the National Forum on Health, Ottawa: National Forum on Health.

Naylor, C. D. (1986), Private Practice, Public Payment, Kingston and Montreal: McGill Queens University Press. 
Noelle-Neumann, E. (1999), 'The Effect of the Mass Media on Opinion Formation', in D. Demers and K. Viswanath (eds), Mass Media, Social Control, and Social Change: A Macrosocial Perspective, Ames: Iowa State University Press, 51-76.

OECD (2015), 'OECD Heath Data 2015', http://stats.oecd.org/Index.aspx? DataSetCode= SHA\# [3 February 2017].

Ontario, Office of the Premier (2017), Free Prescription Medication for Children and Youth Through OHIP + , Toronto: Queen's Printer.

Perry, J. H. (1989), A Fiscal History of Canada, Toronto: Canadian Tax Foundation.

Pierson, P. (2000), 'Increasing returns, path dependence, and the study of politics', American Political Science Review, 94(2): 251-267.

Pomey, M.-P., S. G. Morgan, J. Church, P.-G. Forest, J. N. N. Lavis, T. McIntosh, N. Smith, J. Petrela, E. Martin, and S. Dobson. (2010), 'Do provincial drug benefit initiatives create an effective policy lab? The evidence from Canada', Journal of Health Politics, Policy and Law, 35(5): 705-742.

Romanow, R. J. and G. Marchildon (2015), 'The time has come for universal pharmacare', The Toronto Star, Toronto, 29 October. https:/www.thestar.com/opinion/commentary/ 2015/10/29/the-time-has-come-for-universal-pharmacare.html [1 November 2015].

Royal Commission on Health Services (1964), Report of the Royal Commission on Health Services, Ottawa: Queen's Printer.

Standing Committee on Health (2017), Development of a National Pharmacare Program, Ottawa: Queen's Printer. http://www.ourcommons.ca/Committees/en/HESA/StudyActivity?studyActivityId=8837577 [22 June 2017].

Taylor, M. G. (1987), Health Insurance and Canadian Public Policy, Kingston and Montreal: McGill Queens University Press.

Treff, K. and D. B. Perry (1997), Finances of the Nation 1996, Toronto: Canadian Tax Foundation. Treff, K. and D. B. Perry (1998), Finances of the Nation 1997, Toronto: Canadian Tax Foundation. Treff, K. and D. B. Perry (2002), Finances of the Nation 2001, Toronto: Canadian Tax Foundation. Treff, K. and D. B. Perry (2003), Finances of the Nation 2002, Toronto: Canadian Tax Foundation. Tuohy, C. H. (1999), Accidental Logics, New York: Oxford University Press. 